\title{
A study of household contacts of persons affected by leprosy with a high bacterial index
}

\author{
SENTHILKUMAR RAMASAMYa, ARCHANA KUMAR ${ }^{\mathrm{b}}$ \\ \& PITCHAIMANI GOVINDHARA J \\ ${ }^{\text {a }}$ Former Physiotherapist, Bethesda Leprosy Mission Hospital, Champa, \\ Chhattisgarh, India \\ ${ }^{\mathrm{b}}$ Deputy Superintendent, Bethesda Leprosy Mission Hospital, Champa, \\ Chhattisgarh, India \\ ${ }^{\mathrm{c}}$ Department of Allied Health Sciences, Sri Ramachandra Institute of Higher \\ Education and Research (DU), Porur, Chennai, Tamil Nadu, India
}

Accepted for publication 29 October 2019

\begin{abstract}
Summary
Objective: The study aimed to screen household contacts of persons diagnosed with leprosy having a high bacterial index, at a tertiary referral centre.

Methods: This hospital based study involved 334 persons who were newly diagnosed as leprosy with a high bacterial index, attending a tertiary referral hospital, Champa, Chhattisgarh, India. We enumerated all the household contacts of registered cases and invited them to be screened for leprosy.

Results: Of 334 high BI cases, $252(75 \%)$ were male and $82(25 \%)$ were female, with ages ranging from 12 to 75 years. Sixty two (18\%) had Grade 2 disability and 32\% had a bacterial index of above 5+ at the time of diagnosis. A total of 1,397 household members were enrolled for screening and $678(49 \%)$ were examined for leprosy. One hundred and sixteen household members were found to have signs of leprosy, and among these, $57(49 \%)$ were identified as new cases, $11(10 \%)$ were known cases on treatment and $48(41 \%)$ had been previously treated for leprosy.

Conclusion: This study showed that screening of household contacts of high BI cases is an effective method of leprosy case detection and emphasizes the continuing need to screen and follow up. Continued health education and motivation of household contacts will enhance voluntary reporting for periodical screening.
\end{abstract}

Keywords: Leprosy, bacterial index, contact screening, disability, Chhattisgarh

\section{Introduction}

Leprosy is a chronic infectious disease, causing various physical disabilities and deformities. ${ }^{1}$ It is still endemic and continues to be a public health challenge in developing countries, like India. ${ }^{2}$ Untreated lepromatous leprosy patients are the most infectious and being a household

Correspondence to: Archana Kumar, Deputy Superintendent, Bethesda Leprosy Mission Hospital, Champa, Chhattisgarh, India (e-mail: archana.kumar@leprosymission.in)

Work was undertaken: Bethesda Leprosy Mission Hospital, Champa, Chhattisgarh, India. 
contact of a lepromatous patient is the most important risk factor for leprosy. ${ }^{3,4}$ The risk of leprosy in household contacts when compared to the general population is eight to ten times for the household of lepromatous cases, and two to four times for tuberculoid forms. ${ }^{5}$ Despite worldwide efforts to eliminate leprosy, the number of infected individuals who develop leprosy, is still substantial. Early diagnosis of the disease remains the most effective way to stop the chain of transmission and prevent disabilities due to leprosy. ${ }^{2}$

Persons affected by leprosy with a high bacterial load, release billions of bacilli that can potentially contaminate their close relatives or household contacts. As a result, the contacts of patients with leprosy are known to have a higher risk of illness than the general population. ${ }^{2}$ Surveillance of these contacts would be an easy control strategy to block transmission, as suggested by the World Health Organization. ${ }^{6}$

India is currently operating the National Leprosy Eradication Program (NLEP) to eliminate the disease and it is one of the largest leprosy eradication program in the world. However, more than 100,000 new cases are still reported every year and India has not recorded a drastic fall in new cases since successfully eliminating leprosy. ${ }^{7}$ Even today, stigma leads to late detection of new cases. Household contacts are considered a primary focus for the spread of infection. ${ }^{1}$

A high number of leprosy cases are undetected and not reported by the health services. ${ }^{8}$ Large numbers of early leprosy cases do not reach the health facilities where leprosy treatment is provided, although some chronically ill patients reach at a later stage, and thus multibacillary disease is found more in passive reporting. This may suggest that a large number of established cases are not sufficiently self-motivated or otherwise lack the knowledge to utilize the free diagnostic and treatment services on offer. ${ }^{9}$

Chhattisgarh has the highest prevalence rate (PR) of leprosy in India at 2.54 per 10,000 population and an annual new case detection rate (ANCDR) of 43.69 per 100,000 population for the year April 2016 to March 2017. ${ }^{10}$ This study targeted the examination of household contacts through motivation and educating of persons diagnosed with a high bacterial index (BI of 4+ or more) to bring family members or contacts for screening. We report the outcome of contact screening among persons diagnosed with a high bacterial index.

\section{Methods}

STUDY DESIGN, SETTING AND PARTICIPANTS

This hospital based study was conducted at Bethesda Leprosy Mission Hospital, Champa during the period April 2012 to March 2016. Index cases were newly diagnosed cases registered for multi drug therapy (MDT) with a bacterial index (BI) of 4+ and above, examined by slit-skin smear; their household contacts were invited for screening. Household contacts were defined as those living in the same house and sharing the same kitchen for at least six months prior to the start of MDT.

\section{PROCEDURE}

A physiotherapist experienced in leprosy rehabilitation was assigned to recruit participants. Informed oral consent was obtained from all participants after explaining the study, and confidentiality was promised and ensured. The physiotherapist listed all the household contacts and asked each index case to bring their contacts for screening on a subsequent visit. On every visit, health education was given, focusing on early signs and symptoms of leprosy and its consequences, helping them to screen other family members at home. If they suspected any 
Table 1. Demographic data of cases newly registered for MDT $(n=334)$

\begin{tabular}{|c|c|c|c|c|}
\hline \multirow[t]{3}{*}{ Status } & \multicolumn{2}{|c|}{ Gender } & \multirow{2}{*}{\multicolumn{2}{|c|}{$\frac{\text { Total }}{n=334}$}} \\
\hline & \multirow{2}{*}{$\begin{array}{c}\text { Male } \\
n=252\end{array}$} & \multirow{2}{*}{$\begin{array}{c}\text { Female } \\
n=82\end{array}$} & & \\
\hline & & & $n$ & $(\%)$ \\
\hline \multicolumn{5}{|l|}{ Age in years } \\
\hline Below 18 years & 6 & 9 & 15 & $(4.5 \%)$ \\
\hline 18 to 30 years & 91 & 24 & 115 & $(34.4 \%)$ \\
\hline 31 to 45 years & 98 & 33 & 131 & $(39.2 \%)$ \\
\hline 46 to 60 years & 46 & 12 & 58 & $(17.4 \%)$ \\
\hline Above 60 years & 11 & 4 & 15 & $(4.5 \%)$ \\
\hline \multicolumn{5}{|c|}{ Eye Hand \& Foot Score } \\
\hline Score 0 & 119 & 45 & 164 & $(49.1 \%)$ \\
\hline Score 1 & 24 & 6 & 30 & $(9.0 \%)$ \\
\hline Score 2 & 54 & 20 & 74 & $(22.2 \%)$ \\
\hline Score $3 \&$ above & 55 & 11 & 66 & $(19.8 \%)$ \\
\hline \multicolumn{5}{|c|}{ WHO Disability grade } \\
\hline Grade 0 & 120 & 44 & 164 & $(49.1 \%)$ \\
\hline Grade 1 & 80 & 28 & 108 & $(32.3 \%)$ \\
\hline Grade 2 & 52 & 10 & 62 & $(18.6 \%)$ \\
\hline \multicolumn{5}{|l|}{ Bacterial Index (B.I) } \\
\hline $4+$ to $5+$ & 164 & 62 & 226 & $(67.7 \%)$ \\
\hline above $5+$ & 88 & 20 & 108 & $(32.3 \%)$ \\
\hline
\end{tabular}

Table 2. Results of household contact screening linked to 334 index cases

\begin{tabular}{|c|c|c|c|c|c|c|c|}
\hline \multirow[t]{2}{*}{ Active screening } & \multicolumn{3}{|c|}{ Children (Below 18 years) } & \multicolumn{3}{|c|}{ Adult (Above 18 years) } & \multirow[t]{2}{*}{ Total } \\
\hline & Male & Female & Total & Male & Female & Total & \\
\hline Enrolled & 256 & 231 & 487 & 455 & 455 & 910 & 1397 \\
\hline Screened & 106 & 97 & 203 & 276 & 199 & 475 & 678 \\
\hline \multicolumn{8}{|l|}{ Outcome of screening } \\
\hline New case & 8 & 10 & 18 & 28 & 11 & 39 & 57 \\
\hline Under treatment (UT) & 1 & 1 & 2 & 6 & 3 & 9 & 11 \\
\hline Released from treatment (RFT) & 1 & 4 & 5 & 22 & 21 & 43 & 48 \\
\hline
\end{tabular}

skin lesions, or sensory or motor sensory changes, they were advised to bring those contacts to hospital for confirmation.

\section{Results}

A total of 334 high BI persons were identified and recruited for this study. Of these, $252(75 \%)$ were male and $82(25 \%)$ were female, with ages ranging from 12 to 75 years. 108 cases $(32 \%)$ had Grade 1 disability, $62(18 \%)$ had Grade 2 disability and $108(32 \%)$ had a BI above 5+ at the time of diagnosis (Table 1).

A total of 1,397 household contacts were enrolled and $678(49 \%)$ were examined for leprosy. Among children, 42\% (203/487) were screened and among adults 52\% (475/910) were screened. Among childhood household contacts, similar proportions of each gender reported for screening. Amongst the adults, $61 \%$ of male contacts, and $44 \%$ of females were screened (Table 2). 
Table 3. Demographic details of household contacts with leprsoy $(n=116)$

\begin{tabular}{|c|c|c|c|c|c|}
\hline \multirow[t]{2}{*}{ Status } & \multirow{2}{*}{$\begin{array}{c}\text { New } \\
n=57\end{array}$} & \multirow{2}{*}{$\begin{array}{c}\text { On MDT } \\
n=11\end{array}$} & \multirow{2}{*}{$\begin{array}{c}\text { RFT } \\
n=48\end{array}$} & \multicolumn{2}{|c|}{ Total $(n=116)$} \\
\hline & & & & $n$ & $(\%)$ \\
\hline \multicolumn{6}{|l|}{ Sex } \\
\hline Male & 36 & 7 & 23 & 66 & $(57 \%)$ \\
\hline Female & 21 & 4 & 25 & 50 & $(43 \%)$ \\
\hline \multicolumn{6}{|l|}{ Age in Years } \\
\hline Below 18 years & 16 & 2 & 4 & 22 & $(19 \%)$ \\
\hline $18-30$ years & 19 & 4 & 9 & 32 & $(28 \%)$ \\
\hline $31-45$ years & 13 & 3 & 13 & 29 & $(25 \%)$ \\
\hline $46-60$ years & 7 & 2 & 16 & 25 & $(22 \%)$ \\
\hline Above 60 years & 2 & 0 & 6 & 8 & $(7 \%)$ \\
\hline \multicolumn{6}{|l|}{ Disease Type } \\
\hline Multibacillary (MB) & 27 & 8 & 40 & 75 & $(65 \%)$ \\
\hline Paucibacillary (PB) & 30 & 3 & 8 & 41 & $(35 \%)$ \\
\hline \multicolumn{6}{|l|}{ EHF score } \\
\hline Score 0 & 45 & 8 & 38 & 91 & $(78 \%)$ \\
\hline Score 1 & 5 & 0 & 2 & 7 & $(6 \%)$ \\
\hline Score 2 & 4 & 2 & 1 & 7 & $(6 \%)$ \\
\hline Score 3 and above & 3 & 1 & 7 & 11 & $(9 \%)$ \\
\hline \multicolumn{6}{|l|}{ WHO disability grade } \\
\hline Grade 0 & 45 & 8 & 38 & 91 & $(78 \%)$ \\
\hline Grade 1 & 8 & 1 & 7 & 16 & $(14 \%)$ \\
\hline Grade 2 & 4 & 2 & 3 & 9 & $(8 \%)$ \\
\hline
\end{tabular}

Table 4. Relationship of household contacts with leprosy to the index case $(n=116)$

\begin{tabular}{lccccc}
\hline Relationship to index case & New & On MDT & RFT & \multicolumn{2}{c}{ Total $(n=116)$} \\
\cline { 5 - 6 } & $n=57$ & $n=11$ & $n=48$ & $n$ & $(\%)$ \\
\hline Spouse & 16 & 3 & 6 & 25 & $(22 \%)$ \\
Parents & 6 & 0 & 21 & 27 & $(23 \%)$ \\
Son and Daughters & 22 & 3 & 9 & 33 & $(28 \%)$ \\
Sibling & 11 & 23 & 8 & $(7 \%)$ \\
Others & 2 & $20 \%)$ \\
\hline
\end{tabular}

Of the index cases, 85 (25.4\%) had household contact members affected by leprosy. Among them, $62(73 \%)$ had one household contact affected by leprosy, $17(20 \%)$ had two contacts and $6(7 \%)$ had three or more contacts affected.

Of the 678 screened contacts, $116(17 \%)$ were identified as affected by leprosy, of which 57 were never treated before for leprosy, 11 were currently under treatment with MDT and 48 had completed MDT (Table 2).

Among the 116 contacts with leprosy, $19 \%$ were aged below 18 years and $43 \%$ of them were females. A majority of them (65\%) had the MB form of disease. At the time of screening, $14 \%$ had Grade 1 disability and $8 \%$ had Grade 2 disabilities (Table 3 ).

The relationship of household members affected with leprosy to the index persons included $22 \%$ as spouse, $23 \%$ as parents, $28 \%$ as sons or daughters, $20 \%$ as siblings and $7 \%$ as others. Of the household members affected with leprosy, 65\% (16/25), 67\% (22/33) and 48\% (11/23) were detected among spouses, sons and daughters, and siblings, respectively. Among the parents, $78 \%(21 / 27)$ were previously treated for leprosy (Table 4). 


\section{Discussion}

The health services are responsible for educating and motivating patients to report promptly and adhere to treatment, and for providing holistic health care and quality services. ${ }^{11}$ National leprosy programmes are urged to encourage people to come forward for treatment and to integrate leprosy services within health facilities. ${ }^{12}$ In 2005 , leprosy services in India were integrated with General Health Care services but in the last few years this arrangement has not been able to detect the expected numbers of new leprosy cases, because of the passive mode of case detection leading to large numbers of hidden cases in the community. ${ }^{13}$ This study examined household contacts by motivating and educating new high BI cases to bring their family members or contacts for screening. In an institution-based voluntary household contact screening exercise, there is a chance of self-selection bias amongst the household contacts themselves. However, about $49 \%$ of the household contacts did report for screening for leprosy.

A study from India observed that active case detection reveals that there are a large number of previously undetected leprosy cases in the population. ${ }^{9}$ Untreated, leprosy can cause progressive and permanent damage to the skin, nerves, limbs, and eyes. In this study, 19\% of the high BI index cases reported with Grade 2 disability and 32\% reported with Grade 1 disability at the time of diagnosis. In addition, about one third of them had BI above 5+.

The mechanism of transmission of leprosy consists of prolonged close contact between susceptible and genetically predisposed individuals and untreated multibacillary patients. ${ }^{14}$ The household contacts of MB patients have a high risk of developing disease, ${ }^{15}$ and it was observed in this study that $25 \%$ of index cases reported household contacts members with leprosy, including those newly diagnosed, under treatment and released from treatment.

In children, the source of infection may be an untreated MB leprosy patient within the family or the community. ${ }^{16,17}$ Another study from India shows that $81 \%$ of the pre-existing cases in households were $\mathrm{MB}$, suggesting that these children were not the source of infection, but recipients of infection. ${ }^{18}$ In the present study, among the household contacts with leprosy who were parents, $78 \%$ were previously treated for leprosy.

A study from Nigeria observed that the women are less aware of causation and symptoms of leprosy and have less access to health care coverage, leading to longer periods of delay in female patients before reporting for diagnosis and treatment, compared with males, and a higher proportion with disability. ${ }^{19}$ The females were slower to self-report than the males. ${ }^{20}$ In our study, contacts of adult females reported less frequently for screening than the contacts of adult males.

The World Health Organization launched a five year Global Leprosy Strategy 2016-2020 in April 2016 entitled 'Accelerating towards a leprosy-free world'. It aims at detection of all new cases before they develop disabilities and prompt initiation of treatment so as to ensure they are cured without any residual disability. This will have an impact on the transmission of infection in the community. ${ }^{21}$ It is very important to strengthen health education for household contacts to encourage them in self-reporting, once they suspect possible symptoms and signs of the disease. ${ }^{18,22}$

The Government of India, Ministry of Health and Family Welfare launched the Leprosy Cases Detection Campaign (LCDC) in April, 2016 and it was implemented in high endemic districts of the country. ${ }^{23}$ House to house visits were done to detect hidden and undetected leprosy cases in order to prevent physical disability and deformity by early treatment and to break the chain of transmission at the community level. 
Blanket screening is very resource intensive, so mapping of positive bacterial index cases and child cases, with subsequent screening of household contacts may help to strengthen programmes such as LCDC.

In conclusion, this study showed that screening household contacts of high BI index cases is an effective method for leprosy case detection and emphasizes the continuing need to screen and follow up. Identifying the contacts of patients with leprosy who are at high risk of disease is of utmost importance for the leprosy control programme to interrupt the transmission of disease. Examining contacts includes not only the family members but also the neighbours and other people in the neighbourhood, wherever possible. Continued health education and motivation of household contacts will enhance voluntary reporting for periodical screening.

\section{Acknowledgements}

The authors express sincere thanks to Dr Sandeep Kumar, Superintendent, Bethesda Leprosy Mission Hospital, Champa and Dr Joydeepa Darlong, Head of Knowledge Management, The Leprosy Mission Trust India, New Delhi for their guidance and encouragement. We extend our thanks to the Physiotherapy Department, Bethesda Leprosy Mission Hospital, Champa for their support. We thank to all the participants and their household members in this study for taking part.

\section{Author contribution}

Mr Senthilkumar Ramasamy was involved in study conceptualization and design, obtaining permission for conducting the study, conducting interviews, data collection, data analysis and interpretation, and manuscript writing.

Dr Archana Kumar, was involved in study conceptualization and design, monitoring the study and commenting on the manuscript.

Dr Pitchaimani Govindharaj, was involved in data analysis and interpretation, drafting and finalizing the manuscript for submission.

\section{References}

1 Padhi T, Pradhan S. Family motivation card: An innovative tool for increasing case detection in a resource poor setting. Lepr Rev, 2015; 86(2): 170-175.

2 Sales AM, De Leon AP, Düppre NC, Hacker MA, Nery JA, Sarno EN, Penna ML. Leprosy among patient contacts: A multilevel study of risk factors. PLoS Neglected Tropical Diseases, 2011; 5(3): e1013.

3 Van Beers SM, Hatta M, Klatser PR. Patient contact is the major determinant in incident leprosy: implications for future control. Int J Lepr Other Mycobact Dis, 1999; 67: 119-128.

4 Lockwood DNJ. Commentary: Leprosy and poverty. Int J Epidemiol, 2004; 33: 269-270.

5 Noordeen SK. The epidemiology of leprosy. In: Hastings RC (ed.), Leprosy. 2nd edn., Edinburgh: ChurchillLivingstone 1994; pp. 29-48.

6 Martinez AN, Talhari C, Moraes MO, Talhari S. PCR-based techniques for leprosy diagnosis: From the laboratory to the clinic. PLoS Neglected Tropical Diseases, 2014; 8(4): e2655.

7 Sharma S.. India sees 60\% of new leprosy cases globally, Delhi reports increased prevalence. Hindustan Times, New Delhi. Available from: http://www.hindustantimes.com/india-news/india-accounts-for-60-of-new-leprosycases-globally/story-4KanrZgmTJ8ThBBTCh4RmO.html (Accessed on 21 June 2018).

8 Smith WC, van Brakel W, Gillis T, Saunderson P, Richardus JH. The missing millions: a threat to the elimination of leprosy. PLoS Neglected Tropical Diseases, 2015; 9(4): e0003658.

9 Kumar A, Husain S. The burden of new leprosy cases in India: A population-based survey in two states. ISRN Tropical Medicine, 2013; 329283.

10 National Leprosy Eradication Programme (NLEP). Annual Progress Report 2016-2017. Central Leprosy Division Directorate, General of Health Services, Ministry of Health and Family Welfare Government of India, New Delhi. Available from: http://nlep.nic.in/data.html (Accessed on 15 July 2018). 
11 John AS, Rao PS, Das S. Assessment of needs and quality care issues of women with leprosy. Lep Rev, 2010; 81(1): 34 .

12 World Health Organization, Global Strategy for Further Reducing the Leprosy Burden and Sustaining Leprosy Control Activities 2006-2010 World Health Organization, Geneva, Switzerland, 2005.

13 Jaeggi T, Manickam P, Weiss MG, Gupte MD. Stakeholders perspectives on perceived needs and priorities for leprosy control and care, Tamil Nadu, India. Indian J Lepr, 2012; 84: 177-184.

14 Lastória JC, Abreu MA. Leprosy: Review of the epidemiological, clinical, and etiopathogenic aspects-part 1. Anais Brasileiros de Dermatologia, 2014; 89(2): 205-218.

15 Bakker MI, Hatta M, Kwenang A, Van mosseceeld P, Faber WR, Klaster PR et al. Risk factors for developing leprosy: A population-based cohort study in Indonesia. Lepr Rev, 2006; 77: 48-61.

16 Patil RR. Determinants of leprosy with special focus on children: A socio-epidemiologic perspective. Am J Dermatol Venereol, 2013; 2: 5-9.

17 Souza VF, Silva RS, Valle CL et al. Report of three new leprosy cases in children under fifteen in the municipality of Itaguai, Rio de Janeiro: Event alert for epidemiological investigation. Anais Brasileiros de Dermatologia, 2011; 86: 1011-1015.

18 Ramasamy S, Kumar A, Govindharaj P. Screening household contacts of children diagnosed with leprosy in a tertiary referral centre, Chhattisgarh State, India. Lepr Rev, 2018; 89(2): 117-123.

19 Peters ES, Eshiet AL. Male-female (sex) differences in leprosy patients in south eastern Nigeria: Females present late for diagnosis and treatment and have higher rates of deformity. Lepr Rev, 2002; 73(3): 262-267.

20 Richardus JH, Meima A, Croft RP et al. Case detection, gender and disability in leprosy in Bangladesh: A trend analysis. Lepr Rev, 1999; 70: 160-173.

21 Nation T.. Intensified action needed to reduce leprosy [Internet]. The New Nation. 2017. Available from: http://thedailynewnation.com/news/138021/intensified-action-needed-to-reduce-leprosy.html (Accessed on 21 June 2018).

22 Shen J, Wang Y, Zhou M, Li W.. Analysis on value of household contact survey in case detection of leprosy at a low endemic situation in China. Indian J Dermatolo Venereolo Leprol, 2009; 75(2): 152.

23 Press Information Bureau. Leprosy Case Detection Campaign Government of India Ministry of Health and Family Welfare, New Delhi, 06 September 2016. Available from: http://pib.nic.in/newsite/ PrintRelease. aspx?relid=149557 (Accessed on 12 August 2018). 